\title{
"HIJOS DE LA LIBERTAD", APUNTES SOBRE EL ROL SOCIAL DEL MUSEO HISTÓRICO NACIONAL DE CHILE
}

\author{
"CHILDREN OF FREEDOM", NOTES ON THE SOCIAL ROLE \\ OF THE NATIONAL HISTORICAL MUSEUM OF CHILE
}

\section{SIGAL MEIROVICH*}

RESUMEN: La controversia en torno a la exhibición temporal del Museo Histórico Nacional de Chile (MHN), titulada "Hijos de la Libertad, 200 años de Independencia" (2018), suscitó debate en redes sociales, medios de prensa y espacios académicos. Se acusó al Museo de transgredir un consenso social respecto a la representación del dictador Pinochet y, con ello, de transgredirse a sí mismo como dispositivo estabilizador de sentido colectivo. El presente artículo se concentra en la construcción de ese "sí mismo", poniendo en perspectiva su emergencia y desarrollo. Se concluye que, con o sin éxito, efectivamente el Museo buscaba transgredir la distribución de la red entre poder, saber y memoria que conforma su identidad moderna para ensayar una nueva identidad posible, una que intentaba asumir la complejidad que presenta la construcción de sentido colectivo en el Chile actual.

Palabras clave: Museo Histórico Nacional, controversia, institución disciplinar.

Abstract: The controversy surrounding the temporary exhibition of the National Historical Museum of Chile (MHN) entitled "Children of Freedom, 200 Years of Independence" (2018), sparked a debate on social networks, the media and academic venues. The museum was accused of transgressing a social consensus regarding the representation of the dictator Pinochet and, with it, of transgressing itself as a stabilizing device of collective sense. This article focuses on the construction of this "self", putting its emergence and development into perspective. It is concluded that, with or without success, the museum effectively sought to transgress the distribution of the network between power, knowledge and memory that shapes its modern identity in order to try out a new possible identity, one that attempts to assume the complexity that the construction of collective meaning presents in today's Chile.

Aвstract: National Historical Museum, controversy, disciplinary institution.

Recibido: 2019-02-01. Aceptado: 2020-09-20.

* Magíster en Trabajo Social. Candidata a Doctora en Teoría Crítica y Sociedad Actual, Universidad Andrés Bello, Santiago, Chile. Correo electrónico: s.meirovichschapira@uandresbello.edu. Orcid: https://orcid.org/0000-0002-5751-5780. 


\section{INTRODUCCIÓN}

- L AÑO 2010 PROLIFERARON las actividades conmemorativas con motiUvo del bicentenario de la Independencia de las excolonias hispánicas. Abundante reflexión académica ha abordado los modos en que los países latinoamericanos, a través de sus diversas políticas de conmemoración, disputaron representaciones de la historia de cada nación (Gutman y Molinos, 2012; Vargas Álvarez, 2010, entre otros). Si bien pensadores como Jorge Larraín (2010) invitaron a ver en estos festejos una oportunidad para repensar nuestros Estados e incluso nuestro continente, las celebraciones parecen haber desaprovechado tales oportunidades. Como comentan algunos expertos (Malamud, 2011), esto se debió principalmente a un exceso de nacionalismo (y poco desarrollo de trabajos a escala continental), por un lado, y, por otro, a la primacía de una lógica mercantil en el uso del concepto "bicentenario". Así, argumentan, las conmemoraciones, más que convertirse en una puerta de entrada a la construcción o proyección de transformaciones político-sociales, no lograron ir más allá de una simple promoción de productos públicos y privados.

Entre tales políticas conmemorativas (ceremonias públicas, monumentaria, turismo, etc.), los museos suelen destacar como lugares significativos para trabajar dichas coyunturas al estar asociados a su uso moderno como dispositivos eficaces para la estabilización de sentido. En Chile, el Museo Histórico Nacional (MHN en adelante) participó de las celebraciones del año 2010, principalmente a través de su exposición "La razón del Bicentenario", en la que se expuso la construcción de una nueva subjetividad durante la Independencia de nuestro país, el proceso de auto-comprenderse como ciudadano (en lugar de súbdito) y chileno (a pesar de las enormes diferencias sociales que este concepto englobaba) ${ }^{1}$. Aunque dicha exposición tuvo como centro la construcción jurídico-política y simbólica de la nación y sus sujetos, y no las añejas narrativas sobre victorias militares, no tuvo un efecto vinculante con el presente, es decir, no provocó una reflexión crítica respecto a nuestra ciudadanía actual ${ }^{2}$.

\footnotetext{
${ }^{1}$ Para mayor conocimiento de la exposición es posible visitar el catálogo en línea: https://www. mhn.gob.cl/618/w3-article-85161.html?_noredirect=1.

${ }^{2} \mathrm{Si}$ bien esta afirmación no se basa en un estudio de audiencias exhaustivo que permita dar evidencia empírica respecto a las significaciones dadas por los visitantes, sí se basa en la percepción del equipo de trabajo (del cual yo formaba parte en ese entonces), la escasa aparición en prensa del MHN y la lectura del libro de visitas que, en su mayoría, agradece el carácter informativo y didáctico de la exposición.
} 
Si bien Chile tradicionalmente celebra su Independencia cuando se conmemora la Primera Junta Nacional de Gobierno (18 de septiembre de 1810), es el día 12 de febrero de 1818 cuando se firmó y ratificó el acta de Independencia públicamente. El MHN vio en este "segundo" bicentenario la oportunidad de abordar la construcción nacional con una mirada más reflexiva. Por ello, produjo el año 2018 la exposición "Hijos de la Libertad. 200 años de Independencia”, atendiendo a la necesidad de ir más allá de la ritualidad conmemorativa y preguntándose por los discursos y materialidades que han performado dicho ideario en nuestra cotidianeidad como ciudadanos $^{3}$. Inaugurada el 5 de abril de 2018, esta exposición era parte de un proyecto más amplio que establecía abordar las ideas ilustradas de libertad, fraternidad e igualdad que gatillaron el proceso revolucionario francés, pues es a ellas a las que la república ha apelado de manera recurrente desde sus inicios, incluso en sus momentos más críticos y violentos. En su catálogo indica que esta exposición intenta abordar cómo:

el concepto de libertad posee diversas vertientes: política, social, económica y/o cultural, las que muchas veces son contrapuestas e incluso antagónicas, y cómo, por otro lado, la cultura material vinculada a estos idearios se expresa a través de soportes conmemorativos y simbólicos que buscan hacer perdurar la memoria. (Andrade en Alegría et al., 2018, s.p.)

El objetivo de la propuesta museográfica fue proveer al público la posibilidad de reflexionar acerca de la libertad como un concepto que itera al ritmo del ejercicio constructivo constante de nuestra independencia. Sin embargo, la inclusión de Pinochet junto a la idea de libertad con la que justificara la toma del poder e inaugurara sus años de terror, generó tal controversia que terminó por censurar la trilogía completa de exposiciones y destituir al entonces director, el antropólogo Pablo Andrade ${ }^{4}$ (véase figura $1)$.

\footnotetext{
${ }^{3}$ Cuando se habla de performatividad en este texto, se hace en referencia a su definición más básica inaugurada por John Austin (1982) aludiendo a que la conmemoración no es solo una narración o discurso lingüístico, sino también una materialidad. Se comprende entonces la conmemoración como un acto performativo en tanto práctica semiótico-material que tiene efecto en aquellos que interactúan, donde se entretejen palabras, silencios, imágenes, artefactos, cuerpos y lugares que reproducen interpretaciones del pasado, pero a su vez pueden permitir la emergencia de nuevos campos de sentido.

${ }^{4}$ La autoría de las imágenes de registro de exposiciones y elementos museográficos es del equipo de fotógrafos: Marina Molina, Juan César Astudillo y Claudio López. Los derechos de Copyright@ pertenecen a la "Colección Museo Histórico Nacional".
} 


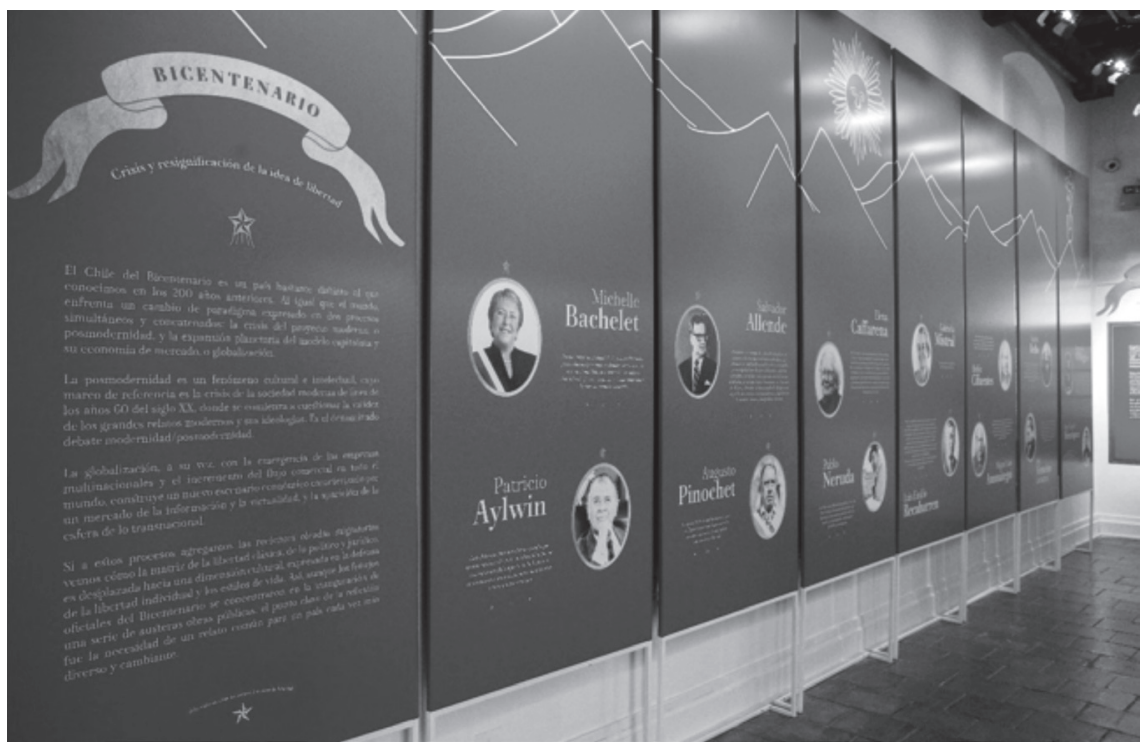

Figura 1. Panel Bicentenario exposición "Hijos de la Libertad. 200 años de Independencia”. Copyright@ “Colección Museo Histórico Nacional”.

La crítica es iniciada por una reconocida artista visual, quien, durante su visita a la exposición, fotografía, recorta y pone en circulación en Redes Sociales (Facebook y Twitter) una imagen del panel en el que se exponía ${ }^{5}$, junto a la fotografía del dictador y el año de emisión, la siguiente cita: "La gesta del 11 de septiembre incorporó a Chile en la heroica lucha contra la dictadura marxista de los pueblos amantes de su libertad". En base a dicha imagen, y a espaldas de la muestra misma ${ }^{6}$, las autoridades de importantes instituciones arremetieron contra la exposición. Las y los máximos representantes del Museo de la Memoria y los Derechos Humanos (MMDH) ${ }^{7}$,

5 "Aislar un objeto de cualquier conexión social o física y preguntar su significado carece de sentido y es tan reduccionista como aislar una palabra dentro de una frase" (M. Maure, 1995, p. 160).

${ }^{6}$ La gran mayoría de las críticas fueron expuestas sin haber visitado la muestra, en base a la imagen recortada y la reflexión teórica respecto a la representación pública del pasado reciente.

${ }^{7}$ Son los museos nacionales las principales alteridades museísticas que contribuyen a la construcción identitaria del MHN. Todos ellos emergieron en el siglo XIX e inicios del XX en un contexto sociopolítico similar (MHN-MNHN-MNBA). Sin embargo, es interesante la irrupción del MMDH, cuarto museo en erigirse con vocación nacional, pero en el siglo XXI. Este museo es la alteridad más relevante en la actualidad en tanto también es un museo de historia (aunque apele a la memoria como concepto articulador diferenciado de la historia) que se sirve del MHN como museo oficialista y conservador para posicionarse en el campo museológico como institucionalidad crítica o contrahegemónica. Si bien no es una hipótesis desarrollada, parece interesante explorar la funcionalidad que cada institución tiene para sus auto-narrativas. 
el Instituto Nacional de Derechos Humanos (INDH) y del Ministerio de las Culturas, las Artes y el Patrimonio, señalaron que la exposición constituía una apología al dictador, un negacionismo ciego o, al menos, un revisionismo irresponsable. Estas críticas derivaron en columnas de opinión y ponencias académicas donde expertos en la materia reflexionaron desde miradas sociológicas, historiográficas y filosóficas (Estefane et al., 2019, pp. 275-300). En tales debates es posible identificar dos núcleos de disputa principales. Uno que versa acerca de los límites y desafíos de la representación de la figura de Augusto Pinochet (y con él del pasado reciente), y otro que versa acerca de la función y/o rol social del MHN (qué puede y debe, o no, ser y hacer un museo estatal de historia). En este último punto llama la atención que, mayoritariamente, se le pide al MHN ser aquello que ha sido desde sus inicios, a saber: un dispositivo de poder donde lo que ingrese a sus arcas sea legitimado como verdadero, clausurado y comunicado unidireccionalmente sin fisuras que permitan interpretaciones alternativas por parte de los visitantes. Se le pide tomar las riendas de la construcción de una (auto)imagen colectiva como si los flujos de lo social no estuvieran haciendo lo propio fuera de los muros del museo, reclamaría Laseca (2015). Para quienes hemos trabajado en museos, sorprende que se acuse al MHN no solo de transgredir un (aparentemente) estabilizado consenso social respecto a cómo representar el pasado reciente, sino también de transgredirse a sí mismo en ello. ¿Qué significa ese "sí mismo" del museo y cuáles son esas supuestas férreas fronteras que se vieron desestabilizadas?

Para explorar dichas preguntas se indagará a grosso modo en la trayectoria del MHN como tecnología moderna y su lento proceso reflexivo. Las fuentes de las que me valdré son principalmente las discusiones académicas derivadas de las columnas de opinión que se publicaron en diferentes medios y que fueron condensadas en una serie de foros en el marco del Coloquio Memorias en Conflicto, patrocinado por el Centro de la Cohesión Social y el Conflicto (COES) (ver Jara, Aguilera y López, 2020, pp. 181-188) y el libro de visitas de la exposición. El objetivo principal es aportar con el contexto museológico de emergencia de esta controversia para no desaprovechar la oportunidad que abre el debate de repensar la musealidad contemporánea en momentos en que la sociedad chilena exige resignificar su historia.

\section{DEL COMPLEJO EXPOSITIVO AL MUSEO HISTÓRICO NACIONAL}

El modelo de museo implantado en Latinoamérica es aquel museo moderno europeo que abre al público los tesoros reales y se consagra a la cons- 
trucción de una idea de lo público y nacional tras la Revolución Francesa. Entusiasmados con los análisis foucaultianos y post-foucaultianos, gran parte de la investigación sobre museos se ha dedicado a observarlos como parte de una serie de instituciones disciplinarias que interpretan y organizan las subjetividades, materialidades, corporalidades y temporalidades modernas. El historiador del arte Douglas Crimp en su ensayo Sobre las ruinas del museo (1993) y el sociólogo Tony Bennett (1995) en The birth of museums han extendido la comprensión del fenómeno principalmente como "complejo expositivo" (p. 59) y la anglosajona Sharon Macdonald como "politics of display" (MacDonald, 1998, p. 1). Autores como Beatriz González y Jens Andermann (2006), en nuestro continente, lo han denominado "galerías del progreso" (p. 13). Básicamente, se observa bajo este prisma al museo como un dispositivo de adiestramiento de la mirada que orienta al visitante sobre formas correctas e incorrectas de dar sentido al nuevo mundo (moderno y republicano) y sus nuevas subjetividades. Desde esta perspectiva, derivada de los estudios culturales, son la Exposición del Coloniaje (1873) y la Exposición Histórica del Centenario (1910) las experiencias fundadoras del complejo expositivo en Chile ${ }^{8}$. Ambas con un gran éxito de acopio de colecciones y de afluencia de público, pavimentan la firma del decreto que crearía al Museo Histórico Nacional volviendo esta tecnología disciplinar permanente en $1911^{9}$. El museo continúa acopiando colecciones a través de la suma de experiencias museales cerradas (como es el Museo del Cerro Santa Lucía, el Museo de Etnología y Antropología, y el Museo Militar), donaciones por parte de los presidentes y de la élite en general, algunas colectas científicas (por ejemplo, las encabezadas por el médico Aureliano Oyarzún ${ }^{10}$ ) y campañas masivas de donación (como las

\footnotetext{
${ }^{8}$ Inaugurada el 17 de septiembre de 1873 en el Palacio de los Gobernadores emplazado en la Plaza de Armas de Santiago, buscaba que el visitante se sumergiera en un tiempo que aparece alejado psicológicamente, aunque no lo sea tanto cronológicamente. Como declaraba el entonces intendente de Santiago, Benjamín Vicuña Mackenna, celebrar esta exposición constituía un acontecimiento fundamental, pues permitía observar la nación en su contraste histórico, entre lo que se describe como la "inercia" del pasado y la "vigorosa" vitalidad del presente (Vicuña Mackenna, 1872-1873, p. 344).

${ }^{9}$ El decreto se firma el 2 de mayo de 1911 bajo el mandato de Ramón Barros Luco y gracias a las gestiones del senador Joaquín Figueroa Larraín, quien pasó a ser presidente del consejo directivo del Museo y es considerado su fundador. Inicialmente ocupó algunas dependencias del Palacio de Bellas Artes y posteriormente dependencias de la Biblioteca Nacional. Hacia 1977 comienza a proyectarse el traslado al edificio de la Real Audiencia, en la Plaza de Armas.

${ }^{10}$ Para profundizar en la relación entre la emergencia de ciertas disciplinas científicas y el museo, ver M. Orellana (1979).
} 
encabezadas por el arquitecto Hernán Rodríguez $\left.{ }^{11}\right)$, lo que lo convierte en un dispositivo tremendamente heterogéneo y con la capacidad de incidir en la construcción social desde disciplinas científicas hasta corporalidades indígenas.

Las múltiples formas en que estas tecnologías modernas han tenido efectos performativos es un hecho que ha sido deconstruido y observado críticamente por expertos en Chile y el mundo ${ }^{12}$, al menos desde la realización de la Mesa Redonda de Santiago de Chile en 1972, conferencia del International Council of Museum de la Unesco (ICOM en adelante) ${ }^{13}$. Dicha conferencia supuso un giro en el modo de comprender el museo teniendo como derivas concretas los ecomuseos y museos comunitarios entre otras experiencias que pretendían desanclar los museos de su concepción tradicional como edificio, colección y público. Hugues de Varine, museólogo participante de esa instancia reflexiva, explica que la nueva museología se sostiene en una concepción expandida y complejizada de dicha triada moderna: territorio, patrimonio y comunidad (De Varine, como se citó en Bolaños, 2000, p. 293).

Sin duda, el concepto de museo y sus prácticas han cambiado a lo largo del tiempo en función de los contextos sociales y las reflexiones disciplinares. Desde su creación en 1946, el ICOM no cesa de reconceptualizar su definición ${ }^{14}$. Para el actual presidente del comité de teoría museológica de

\footnotetext{
${ }^{11}$ La colección de fotografía del MHN, que hoy cuenta con más de 221.541 imágenes que van desde 1840 hasta la actualidad, comenzó a formarse en 1978 gracias a una campaña pública de donaciones liderada por el entonces director.

${ }^{12}$ En el campo de los estudios de museos, como en muchos otros ámbitos del pensamiento social y cultural, el proyecto de desmontaje crítico de estas narrativas ha contado con amplio desarrollo y apoyo (Bennett, 1995; Hooper-Greenhill, 1998; González y Andermann, 2006, y entre otros.) En el contexto nacional, cuya producción es bastante menor, constituye una línea que se consolida cada día más. Buenos ejemplos de ello son los trabajos de las historiadoras Solene Bergot y María José Correa (2016) y de las antropólogas Paulina Faba (2015) y Carla Pinochet Cobos (2016).

${ }^{13}$ Conferencia del Consejo Internacional de museos de la UNESCO en la que se sentaran las bases del movimiento llamado Nueva Museología que busca transformar el museo moderno en cuanto a sus funciones, colecciones, narrativas y públicos (Ver Mostny, 1973). Dicha instancia permitió el desarrollo de la Nouvelle Museólogie en Francia y su materialización en ecomuseos como el Écomusée d'Alsace, New Museology en el ámbito anglosajón se materializa en una narrativa novelesca y una museografía cinematográfica en grandes museos como el British Museum y una Nueva Museología de vertiente latinoamericana que se materializa, principalmente, en museos comunitarios, como la red de museos de Oaxaca en México.

${ }^{14}$ Actualmente, de acuerdo con los estatutos del ICOM adoptados durante la 22a Conferencia General de Viena, Austria, en 2007, un museo es descrito como: “(...) una institución permanente, sin fines de lucro, al servicio de la sociedad y abierta al público, que adquiere, conserva, estudia, expone y difunde el patrimonio material e inmaterial de la humanidad con fines de estudio, educación y recreo" (ver ICOM, 2007).
} 
ICOM (ICOFOM), el brasileño Bruno Brulon et al. (2018), es imprescindible que la pregunta por el museo gire de un ontologismo estático a una pregunta por su capacidad de agencia sobre la(s) experiencia(s) humana(s). En ese movimiento conceptual es posible aprovechar la propuesta de Jean Davallon (2006) de comprender el museo como un "tecnología patrimonial", es decir, como parte de una red de discursos, materialidades y prácticas que permiten construir valores que orientan la construcción de sentido colectivo, pero con el foco en su capacidad de agencia. Si el museo moderno busca orientar hacia una determinada dirección, hoy el museo aspiraría a una auto-comprensión como ámbito fluido de negociación del sentido a través de la vivencia (Morales, 2009). El museo permite un "efecto de realidad", diría Brulon et al. (2018), que otros medios de comunicación de la narrativa histórica no pueden ofrecer. Esto es lo que lo convierte en espacio idóneo de negociación de las diferencias culturales y elaboración de los traumas contemporáneos. En este sentido, el comité internacional de museos arqueológicos e históricos de ICOM, siguiendo al clásico museólogo Georges-Henri Rivière (1993), destaca en cada conferencia internacional la relevancia de que los museos y sitios arqueo-históricos contemplen en sus narraciones las continuidades, las contradicciones, las mutaciones y las aperturas del presente, incluso cuando estas sean dolorosas e incómodas, sin negar su incontestable relación con los poderes dominantes en una sociedad, sino evidenciándolas en cada producto museográfico (ICMAH, 2019).

\section{LOS VAIVENES DE UN PROCESO AUTORREFLEXIVO}

A pesar de haber sido sede de un profundo proceso transformador en la museología internacional en la Mesa de Santiago, nuestro país no lleva adelante estas críticas y propuestas de transformación principalmente debido a la dictadura que irrumpe al año siguiente, dictadura que, mientras reprimió la acción y creación colectiva, promovió la construcción de patrimonio como elemento fundamental para un rediseño forzado del pacto social (Brunner, 1988). El MHN entonces sirvió, entre otras políticas patrimoniales (monumentos, fiestas nacionales, folclor, etc.), para la refundación simbólica del régimen dictatorial entregándole legitimidad y adhesión social además de habituación a las pautas de un nuevo orden autoritario y, con ello, perpetuó la estructura disciplinar de la institución museal decimonónica. Como da cuenta Alegría et al. (2020), los regímenes dictatoriales no modificaron la institucionalidad y normativa patrimonial, sino 
que la utilizaron en beneficio de su visión de país. El MHN proporcionó a las autoridades militares patrimonio religioso para el acto performativo de la jura de una nueva constitución en 1980. Una escultura de madera del siglo XVIII, representando a un Cristo crucificado, ante el cual “juró S. E. el presidente de la República el 11 de marzo pasado (...). Posteriormente, S.E. tuvo la deferencia de enviar a este Museo el original de dicha Acta de Juramento, significativo testimonio que enriquece nuestro patrimonio histórico" (M.H.N., 1981, Boletín N 7, p. 4). Y posteriormente, en 1982, es el mismo Pinochet, junto al arquitecto Hernán Rodríguez, director del museo en ese entonces, quien inaugurará la nueva sede del museo en el palacio de la Real Audiencia, después de una dedicada restauración del edificio, hecho que es agradecido por el museo desde entonces a través de una placa conmemorativa que se encuentra a la entrada del recinto hasta hoy ${ }^{15}$, como se puede observar en la Figura 2, además de conservar como patrimonio nacional una moneda conmemorativa de la jura de la constitución con los retratos en sobrerrelieve del dictador y de los cuatro miembros de la junta militar (véase figura 3).

Durante esa época el MHN comenzó un intenso trabajo de profesionalización de sus áreas y metodologías de trabajo, sin embargo, la exhibición permanente continuaba la decimonónica mirada presidencialista y militar de una historia política. Con posterioridad, y bajo la dirección de la historiadora Sofía Correa (primero) y Barbara De Vos (después), se reestructura la muestra permanente a fines de la década de los 90, se amplía el período histórico representado desde 1930 a 1973, y también se da un giro hacia una museología que pone al centro de su despliegue la idea y no el objeto de colección.

Sin desmerecer estos desarrollos, es recién durante la preparación del aniversario número 40 de la Mesa Redonda antes mencionada, que la museología en Chile parecía remontar el camino crítico. El MHN en particular inicia un proceso lento y tímido de reflexión interna que comienza a manifestarse con su Exposición Aniversario "100 años, 1000 historias 1911-

\footnotetext{
${ }^{15}$ Testimonio material de ello es la conocida placa en la entrada del Palacio de la Real Audiencia, que alberga, con apoyo de la dictadura, al MHN en el kilómetro cero de nuestro país: la plaza de armas de la capital, centro fundacional icónico. Esta placa ha sido objeto de controversia interna desde el regreso a la democracia formal. Durante la dirección de Pablo Andrade se optó por intervenirla museográficamente en vez de retirarla. En concreto, una cédula que acompaña el objeto indica que la placa es una "Inscripción conmemorativa relativa a la restauración y habilitación del Palacio de la Real Audiencia como sede del Museo Histórico Nacional. Realizada bajo la dictadura cívico-militar de Augusto Pinochet. Chile, 1982."
} 


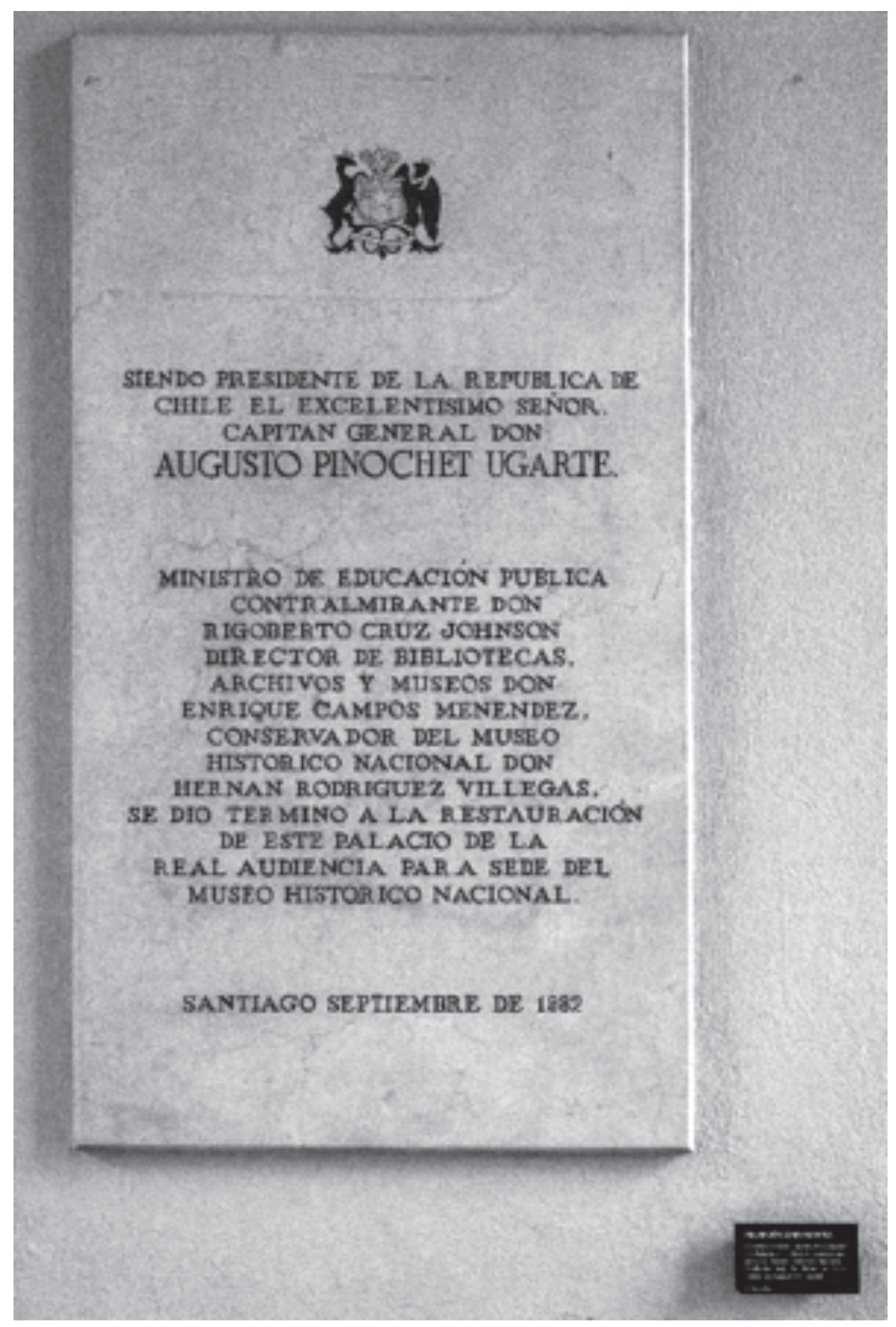

Figura 2. Placa conmemorativa restauración Palacio de la Real Audiencia. Copyright $@$ "Colección Museo Histórico Nacional”. 


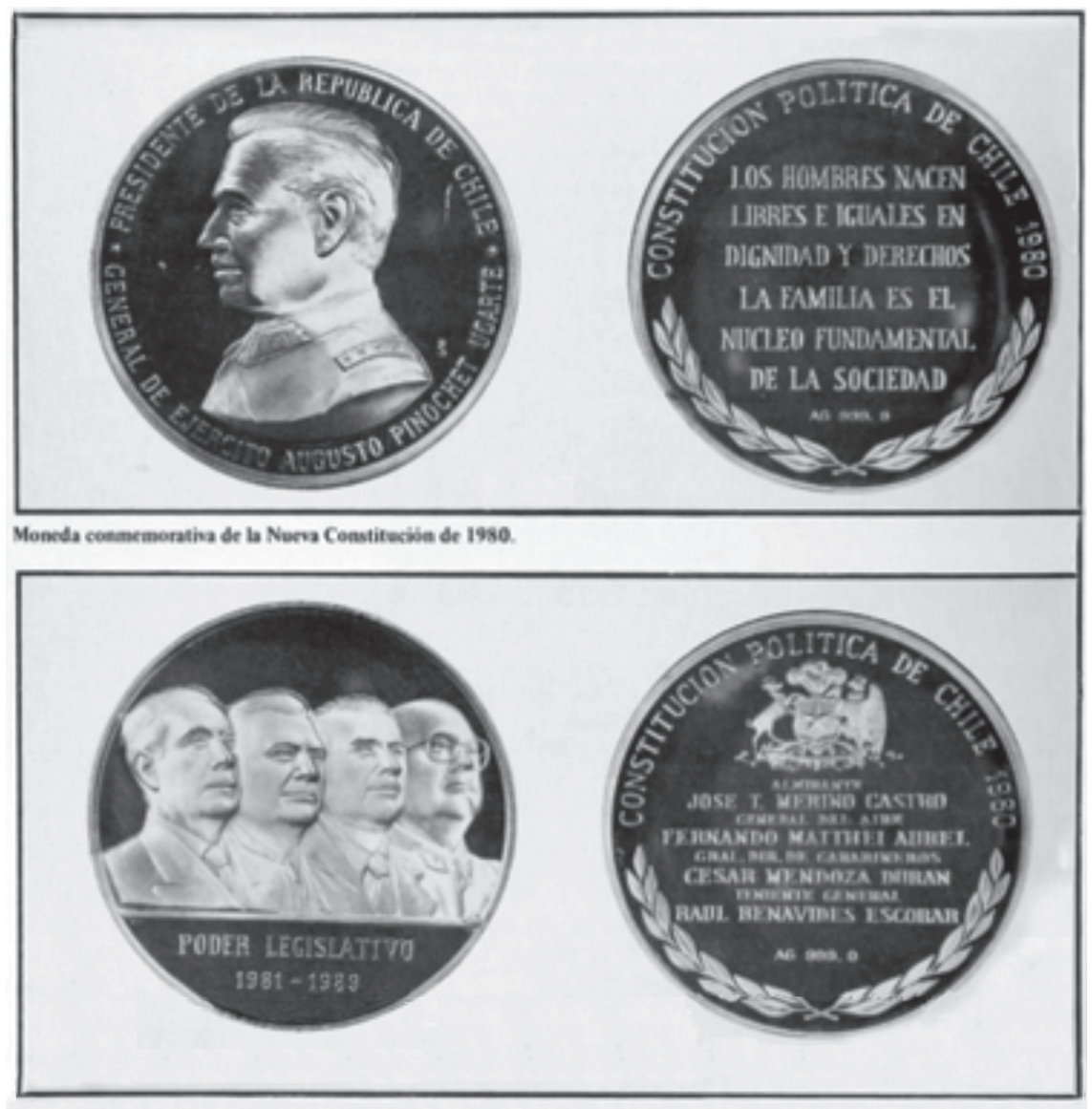

Figura 3. Moneda conmemorativa firma Constitución de 1980. Copyright@ "Colección Museo Histórico Nacional”.

$2011^{\prime 16}$. En ella se dio cuenta del origen de sus colecciones y las políticas de patrimonialización que lo han configurado a lo largo de un siglo, además de sus modos de operación (funcionamiento interno de la institución) actual, develando, sin criticar explícitamente, su constitución material y discursiva asociada a lo que denominamos recién como complejo expositivo (véase figura 4).

\footnotetext{
${ }^{16}$ Catálogo disponible en https://www.mhn.gob.cl/618/w3-article-9736.html?_noredirect=1
} 


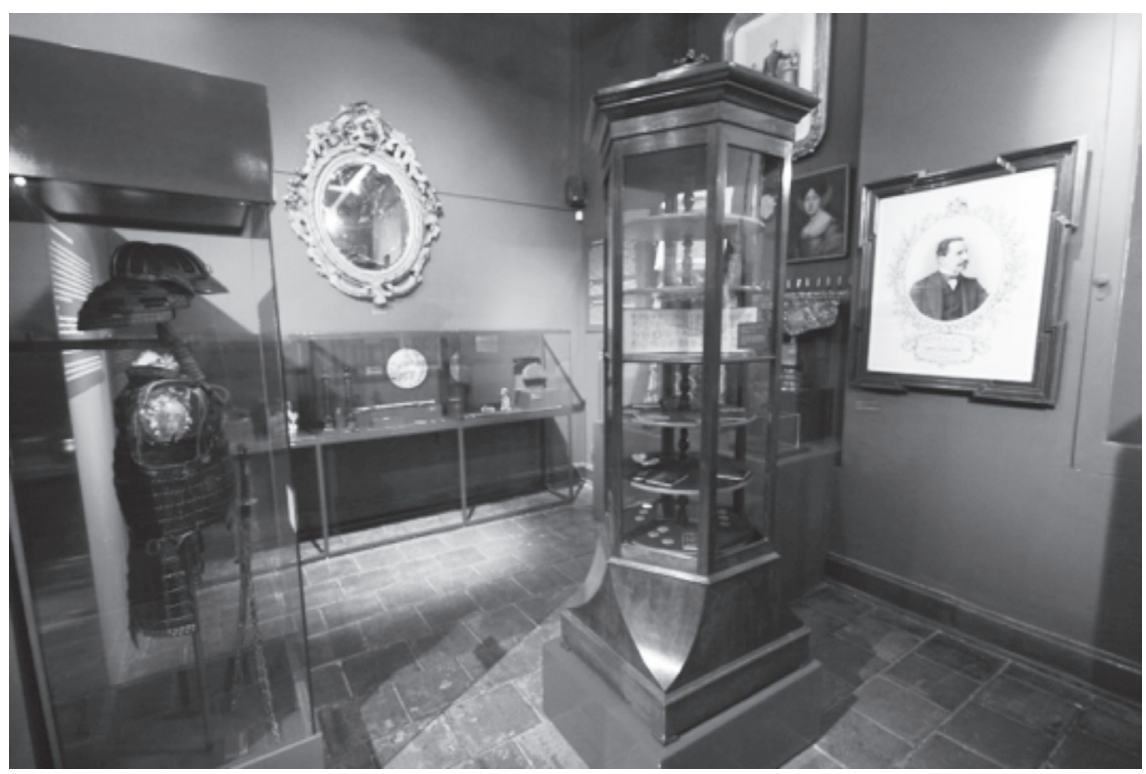

Figura 4. Exposición Aniversario, 100 años 1000 historias. Copyright@ “Colección Museo Histórico Nacional".

Dicho trabajo curatorial constituye la primera vez que un museo en Chile se sitúa a sí mismo como objeto de exhibición y declara con ello que un museo performa en su ejercicio constructivo y expositivo lo que un museo es. Basándonos en una lectura preliminar de la prensa de la época es posible afirmar que este ejercicio autorreflexivo no tuvo mayor impacto en el público, no obstante, sí lo tuvo en los funcionarios, los cuales comenzaron a impulsar coloquios, seminarios, recorridos comentados, foros y exposiciones donde se ensayasen ángulos posibles para una actualización conceptual del museo. Historiadores conocidos por su conservadurismo fueron quienes alzaron la voz crítica cuando se hizo público el proyecto de cambio de guion y la metodología participativa proyectada para ello. En la editorial del diario El Mercurio del 8 de agosto de 2013 el historiador Sergio Villalobos (2013) expone que "este cambio de guion parece envolver más riesgos que ventajas" (p. A3), y se pregunta: “¿A qué reinterpretaciones más o menos antojadizas o ideológicas de la historia pueden dar lugar tales diálogos con la comunidad? ¿No es el museo el que ha de cumplir una función orientadora para la comunidad y no a la inversa?" (p. A3).

Esta reacción al cambio que teme a los efectos performativos del diálogo y deslegitima la capacidad reflexiva de los visitantes, llama públicamente 
al museo a continuar su misión disciplinar en el siglo XXI. Sin embargo, muchos de los profesionales del museo se resisten a ello ${ }^{17}$. La brújula apunta a comprenderse y convertirse en un laboratorio cívico distinto al decimonónico, como indica Bennett (2005). Un laboratorio de código abierto, con mecanismos museales no clausurados (Pinochet Cobos, 2016), donde la co-construcción del imaginario social sea dinámica, contextual e híbrida (Meirovich, 2011). Así lo declara el texto "El Museo Mestizo", del presente año (2019) con el cual comenzó a fraguarse un nuevo proceso re-constituyente del museo incitado por el proyecto de ampliación física. "El pensamiento mestizo -indica el escrito- puede comprenderse en la medida en que se abandonen categorías absolutas y cerradas y se incursione en los espacios intermedios y difusos en donde estas se construyen" (Andrade et al., 2018, p. 18). Dicho marco conceptual para repensar el museo se basa en distintas ideas que circulan y se materializan en el ámbito museológico internacional y particularmente latinoamericano. Una de ellas es la musealidad mestiza que el historiador, crítico y curador de la Universidad de Harvard, Gustavo Buntinx, materializa en el proyecto Micromuseo, al fondo hay sitio. Invitado al coloquio Musealidades Mestizas, expone los objetivos de su proyecto como

una praxis museal que yuxtapone los fragmentos dispersos de nuestras muchas expresiones, recíprocamente iluminadas por sus contrastes tanto como por sus articulaciones. Estrategias friccionarias cuyo principio dinamizador es no reprimir sino productivizar las diferencias. Ubicar en escena crítica el carácter discontinuo de la historia y de la cultura y de la política en una sociedad peruana hecha de fracturas: un país que no es un país, mucho menos una nación, sino un archipiélago de temporalidades dislocadas y ásperamente superpuestas. Una comunidad inimaginada donde ningún presente cancela todos los pasados irresueltos que se derraman, que se derrumban, sobre nosotros. Y sus inercias simbólicas (Buntix, 2015) ${ }^{18}$.

Para explicar de manera más precisa esta opción museológica, el texto mencionado recurre al concepto Ch'ixi con el cual la socióloga boliviana

\footnotetext{
${ }^{17}$ Junto con los diálogos para la construcción de un nuevo guion del año 2013, que surgieron tras la resolución judicial que otorga propiedad al museo (y no a Correos de Chile) del predio contiguo, se realizó el coloquio Musealidades Mestizas el año 2015, los recorridos comentados denominados "Objeto y Discurso" del año 2016, entre otras actividades que convocaron a una multiplicidad de expertos y a la sociedad civil.

${ }^{18}$ Para ver una descripción y análisis acabado del proyecto Micromuseo, revisar Pinochet Cobos (2016).
} 
Silvia Rivera Cusicanqui intenta diferenciarse de la noción de hibridez de Néstor García Canclini y que se emparenta bien con lo que Buntinx pretende abordar con la noción de mestizo. Hibridez, argumenta Rivera Cusicanqui (2010), es una metáfora genética de cuya mezcla saldría una tercera entidad fusionada e inédita, pero estéril, como la mula. Por ello, propone reemplazar lo híbrido por lo ch'ixi como coexistencia en paralelo de múltiples diferencias culturales que no se funden, sino que se relacionan de forma contenciosa y complementaria simultáneamente. Esta palabra aymara, literalmente refiere a un color producto de la yuxtaposición en pequeños puntos o manchas que se confunden para la percepción sin nunca mezclarse del todo. Un color gris, chixi, es blanco y no es blanco a la vez, es blanco y también es negro, su contrario; se confunde.

Es en este contexto de reflexión y reorganización que emerge la exhibición temporal llamada "Hijos de la Libertad. 200 años de Independencia", la cual fue el primer "experimento" de curatoría colectiva que se realizaba en el MHN. Esto tuvo como consecuencia deseada el que la autonomía del curador como figura creadora se diluyera, sin embargo, acarreó consecuencias no deseadas, principalmente una diluida capacidad de respuesta ante la controversia. El resultado fue chi'xi: sucio, manchado, promiscuo, mestizo, teniendo un efecto provocador.

\section{¿Y LOS VISITANTES? EL GIRO MUSEOLÓGICO EN ACCIÓN}

Como afirma Elaine Hooper-Greenhill (1998), el grado de desarrollo de los estudios de público en los museos del mundo es muy desigual. Si bien el MHN ha implementado algunas metodologías cualitativas y cuantitativas, en la práctica las exhibiciones temporales cuentan con el dispositivo clásico como su mejor aliado, esto es, el libro de visitas de escritura manual y libre (cf. Varios, 2018). Atendiendo al hecho de que la exposición solo estuvo abierta al público alrededor de un mes, nuestro acceso posible a los visitantes solo es posible a través de este viejo y fiel dispositivo.

Como ejemplificó brevemente el exdirector, Pablo Andrade, en el Foro de debate organizado por el COES ya mencionado (Andrade, 2018), la reacción expresada durante el primer mes de exposición en el libro de visitas es variada y porcentualmente diferente a lo que podríamos ver en el debate público. La reacción de los visitantes no es dicotómica "a favor o en contra" de lo realizado en la exhibición, y no se concentra mayoritariamente en la inclusión de Pinochet. Es, al menos, más amplia y compleja. Algunos reflexionan en torno al desarrollo evolutivo de la libertad y de la sociedad. 
Argumentan que "seguimos siendo los mismos", "que no ha cambiado mucho Chile en 200 años", que "conmemorar la libertad con la independencia u otro hito histórico invisibiliza el hecho de que es un proceso continuo de construcción y resignificación", felicitando al museo por exponer eso ante el público. Otros interpelan sobre la necesidad de reflexionar en torno a la esclavitud, a lo que sería una esclavitud contemporánea para comprender la libertad hoy. Varios se sintieron llamados a incorporar ideas de libertad a través de citas de otros personajes públicos relevantes o con frases de su propia creación. Junto con ellos, existe gran cantidad de comentarios de inmigrantes que vienen a Chile en busca de "libertad" en distintos sentidos específicos (político, económico, cultural). En algunos de los escritos es posible observar la articulación, crítica, entre la muestra y el presente. Cito uno de los ejemplos más elocuentes: "es inevitable mirar tantas y distintas luchas por la libertad y no cuestionar el actual gobierno, vivimos una época cruel y el privilegio al rico, un gobierno lleno de tráfico de influencias, corrupción política y nepotismo... la lucha sigue en pie, Chile aún no se rinde" (Varios, 2018, Libro de Visitas, 05.05.2018). Todo ello en medio de quienes, al igual que en las redes sociales y prensa, consideraron inaceptable la inclusión de Pinochet en un museo que comprenden como templo.

Asimismo, los profesionales y técnicos del museo que participaron ejecutando el proyecto o como parte de una visita activa previa a la inauguración ${ }^{19}$, reconocen haber comprendido la exhibición gracias a la mediación de sus curadores o por tener antecedentes de los procesos por los que pasaba el museo. Mientras algunos (aquellos que no participaron activamente) critican el despliegue del proyecto museográfico en tanto experimento mal ejecutado, otros se lamentan de que el MHN, a su parecer, deslegitimado como centro de producción de conocimiento ante la academia y desvalorizado como medio de comunicación de masas y entretención, no tuvo apoyo de las comunidades científicas ni museales. Para uno de los curadores "el experimentar sin tener bien claro qué somos y qué función tenemos fue el problema" (Curador, comunicación personal, 11 de diciembre de 2018). Un proyecto experimental que incluya verdades incómodas, como la continuidad y actualidad de la idea libertaria pinochetista en nuestra democracia oficial, es valioso para la reflexión colectiva, sin embargo, resultó evidente que fue ambicioso y requería mayor maduración. El equipo no tuvo la ca-

\footnotetext{
${ }^{19}$ Los funcionarios fueron entrevistados entre septiembre de 2018 y enero de 2019 como parte de mi proyecto de tesis doctoral. Dicho trabajo de campo aún no ha sido analizado sistemáticamente, sin embargo, es posible dar cuenta de algunas ideas comunes en sus relatos respecto a cómo el museo ha implementado transformaciones y en particular cómo se desarrolló esta exhibición.
} 
pacidad de llevar adelante tal experimento y tampoco tuvo capacidad de respuesta asertiva ante la crítica.

A pesar de ello, la exposición fue exitosa para algunos visitantes, tanto para los trabajadores del ámbito museal como el público general, al poner en tensión su discurso tradicional moderno de la historia como progreso y del museo como dispositivo disciplinar. Logró visibilizar que la construcción del ideario político no es un horizonte universal consensuado, sino un campo en disputa que se resignifica de manera contingente ¿Cuánto del Chile actual podríamos haber aprendido de esta muestra, y las que le iban a suceder (Fraternidad e Igualdad), si imagináramos al museo como comunidades de aprendizaje (Rodrigo y Collados, 2015) y no como dispositivos de adoctrinamiento? (Véase figura 5).

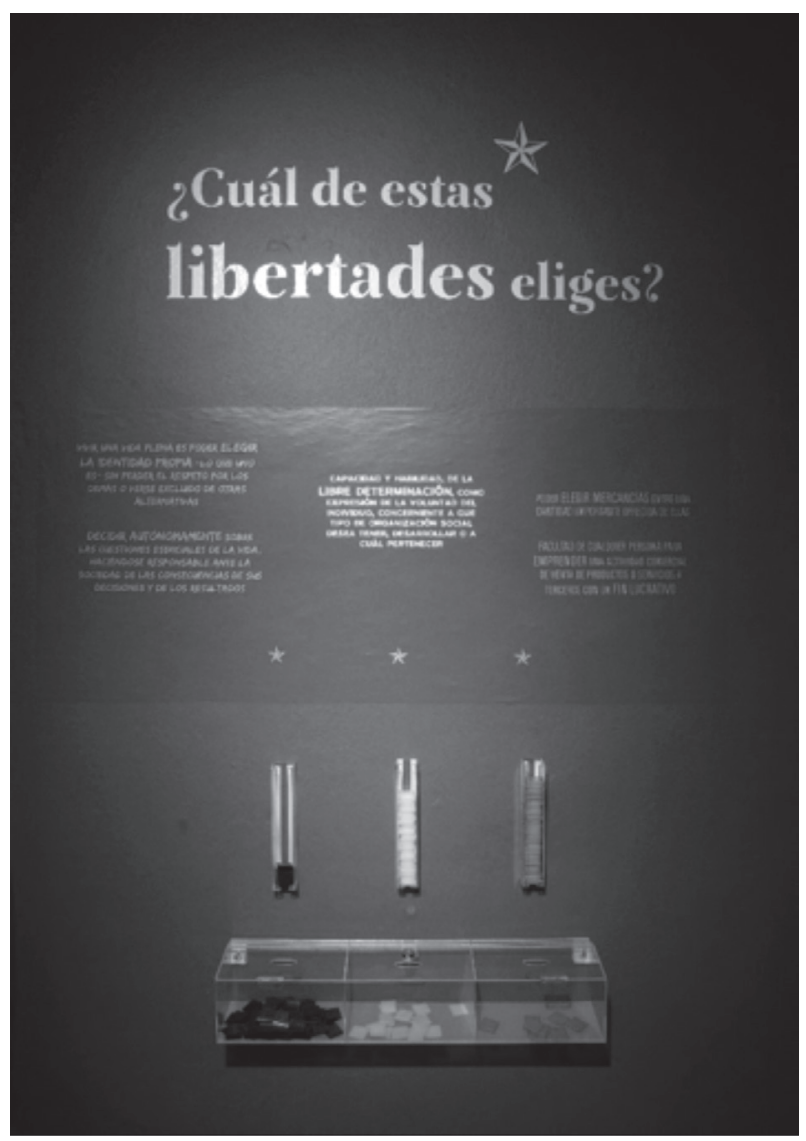

Figura 5. Dispositivo de mediación exposición "Hijos de la libertad. 200 años de independencia”. Copyright@ “Colección Museo Histórico Nacional”. 
Hoy nos enfrentamos a un contexto donde la disputa por los idearios nacionales ha estallado en la calle y se requiere extremadamente de espacios para disentir, dialogar y negociar el sentido de un "nosotros" con vistas a un próximo proceso constituyente. La censura le impidió al museo probarse como plataforma de debate y lamentablemente tras el "estallido social" tampoco ha logrado posicionarse como actor ni como espacio para ello.

El MHN estaba en una búsqueda experimental por expandir sus fronteras, se desestabilizó el supuesto latente de que un museo disciplina, al modo de la escuela o glorifica al modo de un templo. Si bien esta exploración no nos permite confirmar una hipótesis respecto a las motivaciones de la crítica y la censura, sí nos permite concluir que: primero, ese "sí mismo" del museo al que aluden en prensa los críticos de la exposición corresponde al museo moderno que emerge del desarrollo del complejo expositivo en América Latina y que ha cumplido históricamente un rol disciplinar en sentido foucaultiano. Segundo, que efectivamente el museo pretendía transgredir dicha identidad.

\section{CONCLUSIONES}

El presente texto no ha tenido como propósito la defensa de la exposición concreta como artefacto museográfico, sino una defensa museológica en tanto búsqueda disciplinar de re-imaginarse como un actor social capaz no solo de estabilizar visiones hegemónicas, sino también de evidenciar la contingencia y complejidad de las visiones que contribuye a construir. En este caso, particularmente sensible, el gesto requería sin duda de un desarrollo profesional más riguroso, sin embargo, la intención de vincular a Pinochet con la idea de libertad no responde a la ceguera moral de un equipo curatorial ni a una actitud negacionista, sino a una realidad histórica que nos interpela en el presente, donde la idea de libertad pinochetista pareciera tener, a pesar de la aplastante negación normativa, una cotidiana normalidad.

El museo (como cualquier realidad existente) emerge como actor de manera dinámica y contingente, su rol social como estabilizador de sentidos y construcción de consensos no es necesario (ni imposible). Lo que se ha pretendido visibilizar aquí, es que el movimiento iniciado por el MHN apuntaba justamente a la dirección opuesta, a saber: hacia la construcción de sentidos móviles y realidades complejas que no temen incorporar sus zonas grises asumiendo los riesgos que un experimento así puede tener. 
Esta es una reflexión preliminar nacida de la perplejidad que los trabajadores de museos sentimos ante tal episodio y que solo alcanza a ser enunciada en estas páginas. Sin embargo, abre una interesante línea de investigación pragmática que se pregunte qué es y hace el MHN en acción y cómo los ensamblajes socio-técnicos de elementos heterogéneos que se co-constituyen mediante la ejecución reiterada y conjunta de materialidad y discurso (Latour, 2005), permiten que emerjan los museos como dispositivos de construcción de sentido colectivo.

Para concluir, el MHN efectivamente buscó transgredir la distribución de la red entre poder, saber y memoria que conforma el museo moderno. Pero no porque procure negar, relativizar o dar la espalda a una supuesta realidad objetiva ni a la estabilización de verdad conquistada por los movimientos de DD.HH., por el contrario, el museo buscaba sumergirse en su turbulencia desestimando la actitud ingenua (o arrogante) de pretender saber a priori cómo esa realidad está hecha. El férreo esqueleto moderno que le dio vida es, intencionalmente o no, restaurado por quienes ostentan las voces hegemónicas.

Ante esto, cabe recordar, citando a Juan José Saer (2014), que aquello que los museos contemporáneos, y no solo los de arte, se plantean con estas transgresiones "no es una claudicación ante tal o cual ética de la verdad, sino, la búsqueda de una un poco menos rudimentaria" (p. 18).

\section{REFERENCIAS}

Alegría, L., Andrade, P., Arriagada, P., Covarrubias, M., Martínez, J., y Silva, B. (2018). Hijos de la Libertad. 200 años de Independencia. Santiago: Museo Histórico Nacional de Chile.

Alegría, L., Gänger, S., Meirovich, S., Núñez, G. y Polanco, G. (2020). Historia, museos y patrimonio. Discursos, representaciones y prácticas de un campo en construcción, Chile 1830-1930. Santiago: Ediciones Subdirección de Investigación del Servicio Nacional del Patrimonio de Chile.

Andrade, P. (2018). Foro Representaciones de la historia reciente y perpetradores en museos del Estado: Límites, Desafíos y Dilemas. Organizado por el Centro de Conflicto y Cohesión Social (COES), Santiago, Chile.

Andrade, P., Mellado, L., Rueda, H. y Villar, G. (2018). El Museo Mestizo. Fundamentación museológica y disciplinar para el cambio de guion. Santiago: Museo Histórico Nacional de Chile.

Austin, J. L. (1982) [1962]. Cómo hacer cosas con palabras: Palabras y acciones. Barcelona: Paidós.

Bennett, T. (1995). The Birth of the Museum: History, Theory, Politics. London and New York: Routledge. 
Bennett, T. (2005). Civic Laboratories: Museums, Cultural Objecthood and the Governance of the Social. Cultural Studies, 19(5), 521-547.

Bergot, S. y Correa, M. J. (2016). Chile y la escenificación de su modernidad. Ciencias y técnicas en las exposiciones universales nacionales (1869-1888). En M. J. Correa, A. Kottow y S. Vetö (eds.). Ciencia y espectáculo. Circulación de saberes científicos en América Latina, siglos XIX y XX (pp. 47-69). Santiago: Ocho Libros.

Bolaños, M. (2000). La memoria del mundo, 100 años de museología 1900-2000. Madrid: Editorial Trea.

Brulon, B., Brown, K., \& Nazor, O. (2018). Defining museums of the 21st century: plural experiences. Papers from the ICOFOM symposia in Buenos Aires, Rio de Janeiro and St Andrews (pp. 163-168). Paris: ICOM/ICOFOM. ISBN electronic version: 978-92-9012-440-5.

Brunner, J. J. (1988). Un espejo trizado. Ensayos sobre cultura y políticas culturales. Santiago: Flacso.

Buntinx, G. [Museo Histórico Nacional]. (2015, noviembre 17). Musealidad mestiza, musealidad promiscua, musealidad plebeya. La praxis de Micromuseo. En Coloquio Internacional Musealidades Mestizas. [Archivo de video]. Museo Histórico Nacional de Chile. Santiago: recuperado de https://www. youtube.com/watch?v=bZEn2Crq76A\&t=243s

Crimp, D. (1993). On the Museum's ruins. Cambridge: MIT press.

Davallon, J. (2006). Le Don du patrimoine: Une approche communicationnelle de la patrimonialisation. Paris: Hermès Sciences-Lavoisier.

Estefane, A., Olmedo, C. y Thieleman, L. (2019). 1988-1968: de la Transición al '68 en Chile', una retrospectiva crítica de la segunda mitad del siglo XX en Chile. Santiago: Ariadna Ediciones.

Faba, P. (2015). El «carácter» de lo sensible. La exhibición del pasado en el Chile del Siglo XIX. Revista de Teoría del Arte, 25, 39-64.

González, B. y Andermann, J. (eds.) (2006). Galerías del progreso. Museos, exposiciones y cultura visual en América Latina. Rosario: Beatriz Viterbo Editora.

Gutman, M. y Molinos, R. (2012). Construir bicentenarios en la era de la globalización. Buenos Aires: Ediciones Infinito.

Hooper-Greenhill, E. (1998). Los museos y sus visitantes. S. L, Gijón, Asturias: Ediciones Trea.

International Council of Museum (ICOM) (2007). Resoluciones aprobadas por la 22a Conferencia General de Viena. Austria. Recuperado el 25.07.2019 en https://icom.museum/wp-content/uploads/2018/07/ICOMs-Resolutions_ 2007_Esp.pdf

International Committee for Museums and Collections of Archaeology and History (ICMAH) (2019). Reconsidering Museums Versus Contemporary Archaeology. Annual Conference in Kyoto, Japan. Recuperado el 02.02.2020 en http://icmah.mini.icom.museum/publications-2/our-publications/

Jara, D., Aguilera, C. y López, L. (2020). Límites y dilemas de la representación 
de los perpetradores de violaciones a los derechos humanos en espacios públicos. Atenea, 521, 181-188. doi: 10.29393/At521-1ECRR10001.

Larraín, J. (2010). Identidad chilena y el bicentenario. Revista Estudios Públicos, 120, 5-30.

Laseca, R. (2015). El museo imparable. Sobre institucionalidad genuina y blanda. Santiago: Metales Pesados.

Latour, B. (2005). Reensamblar lo social. Buenos Aires: Ediciones Manantial SRL.

Macdonald, S. (ed.). (1998). The Politics of Display. London: Routledge, https:// doi.org/10.4324/9780203838600.

Malamud, C. (2011). Un balance de los bicentenarios latinoamericanos: de la euforia al ensimismamiento. Real Instituto Elcano. Recuperado el 15.05.2020 en http://www.realinstitutoelcano.org/wps/portal/rielcano_es/ contenido?WCM_GLOBAL_CONTEXT=/elcano/elcano_es/zonas_es/dt12011.

Maure, M. (1995). The exhibition as theatre. On the staging of museum objects. Nordisk Museologi, 2, 155-168. Disponible en https://journals.uio.no/ museolog/article/view/3729.

Meirovich, S. (2011). Preservación dinámica: la protección del patrimonio cultural inmaterial como intervención social (Tesis para optar al grado de Magíster en Trabajo Social). Santiago, Pontificia Universidad Católica de Chile.

Museo Histórico Nacional (M.H.N.) (1981). Boletín No 7. Recuperado el 10.04.2020 Disponible en https://www.mhn.gob.cl/sitio/Contenido/ Colecciones-digitales/73537:Boleti-n-del-Museo-Historico-Nacional-1978-1981.

Morales, L. G. (2009). Límites narrativos de los museos de historia. Alteridades 19(37), 43-56.

Mostny, G. (1973). The Role of Museum in Todays Latin America. Revista Museum 25(3), 176-178.

Orellana, M. (1979). Compilación, introducción, notas y bibliografía al texto. Estudios antropológicos y arqueológicos de Aureliano Oyarzún Navarro. Santiago: Editorial Universitaria.

Pinochet Cobos, C. (2016). Derivas críticas del Museo en América Latina. Ciudad de México: Siglo XXI Editores.

Rivera Cusicanqui, S. (2010). Chixinakax utxiwa: una reflexión sobre prácticas $y$ discursos descolonizadores. Buenos Aires: Tinta Limón.

Rivière, G. H. (1993). La museología (Traducción Antón Rodríguez) Madrid: Ediciones Akal.

Rodrigo, J. y Collados, A. (2015). Retos y complejidades de las prácticas artísticas colaborativas y las pedagogías colectivas. Pulso. Revista de Educación, $38,57-72$.

Saer, J. (2014). El concepto de ficción, 4a ed. Buenos Aires: Seix Barral.

Vargas Álvarez, S. (2010). Después del bicentenario: políticas de la conmemora- 
ción, temporalidad y nación Colombia y México. Bogotá: Editorial Universidad del Rosario.

Varios (2018). Libro de Visitas Exposición "Hijos de la Libertad. 200 años de independencia”. Museo Histórico Nacional de Chile. Revisado el 10.05.2018.

Vicuña Mackenna, B. (1872-1873). La Exposición del Coloniaje. Carta Familiar a Monseñor J. Ignacio Víctor Eyzaguirre. Revista de Santiago tomo II, 341-355. Disponible en: http://www.bibliotecanacionaldigital.gob.cl/visor/ BND:298251.

Villalobos, S. (2013). Museo Histórico: ¿Revisión del guion? Columna de opinión. El Mercurio 8 de agosto, A3. 